Gefuhl'? One may say, I think, that his interpretation of the order is perfectly natural and justifiable. He instinctively takes up that mental attitude which favors the feeling at the expense of the other contents of consciousness. One must also say, however, that the interpretation is naïve. With more introspective experience, he gives a narrower meaning to his instructions; he purposely abstracts from sensible processes, and tries actively to attend to the affective contents as such. "It may be remarked further," say Zoneff and Meumann, "that the better an observer is practised in self-observation the more does he incline to analyze the feeling, and not to enjoy it or thrust it from him" (ibid.). Now Zoneff and Meumann are themselves taking a non-committal position as regards systematic questions ( $c f$. Meumann's Remarks on Terminology, loc. cit., 2). They may, therefore, for the time being, accept the naive observer's interpretation at its face value, and classify his reactions as instances of 'simple attention to feeling.' But a psychology must go farther. How does a 'mere direction of the attention upon' a process differ from an 'analytic attention' to it? Why should the two forms or modes of attention lead to diametrically opposed affective results? I have committed myself to the view that attention, in the first case, is a passive attention to the sensible substrate of the feeling, while in the second case it is a baffled or misdirected active attention. The view is tentative, but it has at least the advantage of setting the two groups of facts in systematic relation. And I see no reason, in anything that they have so far written, why Zoneff and Meumann should not accept it.

Cornell University.

E. B. Titchener.

\title{
ON MCDOUGALL'S OBSERVATIONS REGARDING LIGHT- AND COLOR-VISION.
}

Mr. W. McDougall published in the January, April and July numbers of Mind, I 901 , three papers entitled: 'Some New Observations in Support of Thomas Young's Theory of Light and Colour Vision.' Mr. McDougall there described some fifty experiments which he had made, and drew certain conclusions from them. On the basis of these observations he would reject the Hering-Muller theory of lightand color-vision and substitute for it a modified form of Thomas Young's theory. Mr. McDougall's observations present an extensive array of ingenious devices and of suggestive facts, but in the interpretation of such an amount of material it is perhaps inevitable that some 
few points should be called in question. The purpose of this com. ment is to suggest :

(a) That these experiments do not in every particular warrant the conclusions drawn from them.

(b) That there are certain facts which offer difficulties for the Young-McDougall theory.

(c) A general reason why the Hering-Müller type of theory is preferable to the other.

Mr. McDougall's position is outlined in what follows. He begins with the remark, "that all writers assume that the physiological and psychological processes in the visual areas of the cortex run exactly parallel to retinal processes.' What can such a statement mean? is not every act of selective attention among visual stimuli a case where cortical and retinal processes are not exactly parallel? Are not visual reflexes one kind of instance, and subliminal stimulations another, in which peripheral excitation and consciousness are disparate? Yet what is commoner or more obvious? What does Mr. McDougall sup. pose that psychologists mean by the distinction of central and peripheral? Surely this difference is not a new observation. However, this disparity of cerebral and retinal process is illustrated at some length, and this is, he says, the basis of his theory.

On the retinal side $\mathrm{Mr}$. McDougall assumes that there are fous exciting substances, which he calls the red, green, blue and white $(R$. $\mathrm{G}, \mathrm{B}$, and $\mathrm{W}) \boldsymbol{x}$-substances. When light acts upon the retina it fies (by decomposition) these substances, and by a further chemical process (combination) they each excite their corresponding nerve endings, that is, the termini of four distinct color-systems, R, G, B and W cerebro-retinal systems. Light of any color sets free all four kinds of substances but acts most vigorously on one; thus $R$ light frees $B, G$ and $W$, but it frees $R$ in greater quantity, hence the predominance of red sensation. These substances are highly diffusible, so that when they are freed in any definite part of the retina they tend to diffuse themselves into surrounding areas and there give rise to sensations.

This is the entire retinal basis for the phenomena of light and color vision; all variations not referable to these processes must be explained in cerebral terms. Thus yellow sensation is a psychical fusion of red and green, and the experience black is the inhibition or lack of sensation.

The particular point at which the Hering theory (and Muller's as well) is attacked is in the discussion of the facts of simultaneous and successive contrast and indaction. The case of white light is ex- 
plained first. In simultancous induction the directly stimulated area of the retina diffuses the $x$-substances into adjoining parts and they there give rise to sensations. Succcssive induction is the persistence of white $x$-substances in those areas. In simultaneous contrast the cortical processes excited by a $W$ patch of light tend to inhibit all those from the rest of the visual field. Successive contrast is the case where the cortical processes excited by $x$-substances diffused into outside areas come to predominate over those aroused by the directly stimulated part, that is, where the after-image appears as a white halo around a black area.

Black sensation is in each case the result of cortical inhibition.

He then goes on to explain all contrasts and after-images of colored lights in terms of the cortex. The principle underlying color-contrast is that $W$ being the resultant of the simultaneous activity of the $R$, $G, B$ color-systems, the inhibition of W by $W$ involves the inhibition of $R$ by $R, B$ by $B$ and of $G$ by $G$. Now if the retina be stimulated by a patch of red on a gray background, the $R$ tends much more strongly to inhibit the $R$ in the gray ground than the $B, G$, which the patch of red contains tends to inhibit the $B, G$ of the ground, hence the effect of simultaneous contrast. Successive contrast, or the case of the complementarily colored after-image, is explained by cortical changes, and simultaneous and successive induction or colored light are closely analogous to those phenomena in the case of white light.

Inhibition with Mr. McDougall means always cortical inhibition, but for $R, G, B$ and $W$ he allows a retinal origin which he denies to black. This brings us to the principal difference between the Hering and McDougall theories, which is that Hering assigns a special retinal process as the correlative of the sensation black, whereas Mr. McDougall maintains that no such independent process exists and that the physiological basis of black sensation is simply cortical inhibition.

In support of his general position $\mathrm{Mr}$. McDougall makes a very interesting and exhaustive study of all forms of retinal rivalry, and he states most ably the important part played by the cortex in light- and color-vision. In connection with details of his theory, however, he adduces, among others, the following experiments:

I. See Observations 16, I7, I8 and 19, Article I. The discussion here is whether the relation of black to white is the same as the relation of other colors to their complementaries in the matter of successive contrast or the negative after-image. The first observation was made on a disc white at its center and shading gradually out to black against a black ground. After fixating this disc of shaded black and 
white no negative after-image, only a positive one, was seen. After this colored discs constructed in the same way were used, for example, a disc with a blue center shading gradually out to black. In this case a negative after-image was observed. This experiment is taken as evidence that black cannot excite an after-image of complementary tone in the way that other colors excite their complementaries, but it is obvious that for such a demonstration this experiment cannot be correctly organized. Mr. McDougall is comparing the reactions of different pairs of colors, and if, as the first member of the comparison, he takes a disc shading by many gradations between the complementaries white and black, he ought logically to take as his second case a disc, say, of blue gradually shading into yellow, or of red merging by degrees into green. If he wants to compare black with other colors he must take them under like conditions. For the purpose of such a comparison it does not have the slightest point to contrast black shading up to white, with blue shading off to black.

2. Mr. McDougall wishes to prove that the after-image and the direct image have their seat in the same part of the cerebro-retinal system. He fixated for a few seconds a patch of red light (Obs. 9) and then planted its green after-image beside the red patch. The red and green then faded and reappeared together. This proves, he says, that they are affected in the same way by the same factors, and that the seat of the after-image is in the retina.

A little farther on (Obs. 14) Mr. McDougall showed that an afterimage may be inhibited by a direct image on a different part of the same retina. Why not say that this proves that the two are not affected in the same way by the same factors, and that the after-image is, therefore, not in the retina? It seems curious that $\mathrm{Mr}$. McDougall should not bring in other available evidence if he thinks the retinal location of the after-image requires proof. He might quote not only the experimental results of Exner, but certain striking facts of common observation, $e$. $g$., that the after-image follows every movement of the eye-ball.

3. Yellow sensation, he holds, is due to the psychical fusion of red and green. This is proved by the facts: $(a)$ That the mixture of red and green give a yellow of good saturation (Obs. 49); (b) that the cycle of color in the after-image of yellow shows markedly a red and a green phase (Obs. 41). But what does Mr. McDougall say to the fact that in peripheral color-vision we can see yellow with elements of the retina which are absolutely insensitive to the difference of red and green? 
In this connection he quotes Mrs. Franklin's criticism on the theories of Gegenfarben, in which she says that the red and green, which subjectively are most saturated, are not complementary (antagonistic), but that they produce yellow. But this observation gives no countenance to a psychic fusion theory of yellow, since we have in Mrs. Franklin's own words a more plausible explanation in retinal terms: "Blue and yellow are complementary colors, but red and green, when acting in conjunction, re-compose the yellow-producing substance out of which they have been developed, instead of together making white" (Psychological Review, January, i $\$ 99$ ).

4. On the basis of one experiment (Obs. 22) Mr. McDougall disputes the fact of the simultaneous contrast effect of black. Against this position we may quote the results of Hering, Mach, Sherrington and others. In the following simple test it seems scarcely possible that one should fail to get this effect.
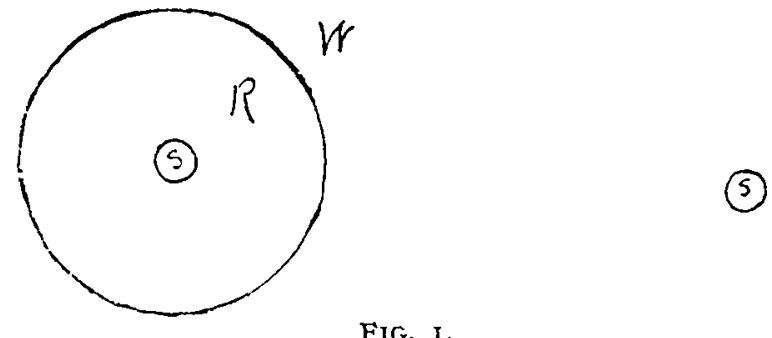

Fic. I.

On a white ground (Fig. I) lies a circular red patch three centimeters in diameter with a black spot at the center. Fixate the black spot for five or six seconds and the red will begin to show dark at the edges and bright red immediately around the spot, while between the dark and the bright red there still lies a broad ring of the unaffected color. Now transfer the after-image to a white ground and center it on a black spot like the first one. In a few seconds a rim of brilliant white light appears to radiate from around the black spot.

5. In the case of the binocular combination of color Mr. McDougall rests in absolute security. Here the fusion seems unquestionably to be a psychic one; but in view of the strong sympathetic connection, upon which he dwells, between the cerebro-retinal systems of the two eyes, is there not a retinal explanation at least possible even here? We may conceive that the blue which excites one retina finds a slight response in the other, while the red which is acting on the second retina is echoed in the first, so that the resulting purple is after all based upon retinal fusion. 
6. In observation 24 there is reproduced an experiment of Muller's, in which dark red against a black ground is compared with the same red against a white ground.

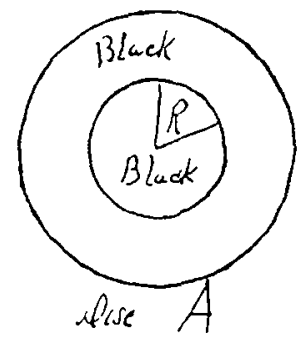

FIG 2.

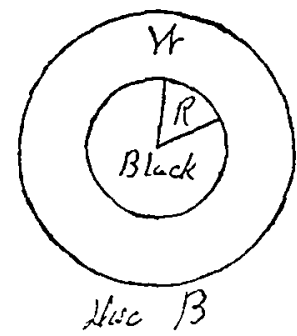

Upon rotating the two discs (Fig. 2) the red of $A$ appears more saturated than the red of $B$. One would suppose that the result might be explained as a mixture of red with contrast white in disc $A$ or a mixture of red with contrast black in disc $B$; but Mr. McDougall rejects such a view, without giving any definite reason, and he says that in disk $B$ the white of the background inhibits the white which the red light contains and hence makes that red still darker.

Many of these experiments are extremely interesting and valuable in themselves, but one could scarcely agree that they support unequivocally any theory which has been advanced in these papers. In fact the conclusions seem often a trifle premature and the above citations serve to illustrate that some of them are logically a little surprising.

If $\mathrm{Mr} . \mathrm{McDougall}$ is to maintain the theory that there is no blackexciting process in the retina, but that black is the inhibition or absence of sensation, he has still one or two questions to answer:

I. If contrast black is the result of suppression of faint gray light by a bright white light, that is, if it is a case of cortical inhibition, why does it persist when we expressly attend to that part of the field in which it appears, why does the faint gray light not emerge into consciousness?

2. If black is mere lack of sensation, why do we not see black with the blind spot in monocular vision?

3. If black is a negative element, why does a mixture of black with other colors change not only their saturation, but their color-tone as well.

4. Subjectively, black is not a 'neutral' color, nor is gray a mere diminution of white; gray appears to us something qualitatively very different from white, like the mixture of some positive element with white. The following observation may touch this point: In mixing 
complementaries on the color-wheel, if the colors differ in luminosity so that the flicker is pronounced, $e . g$. , in blue and yellow, it is noticed that the field suddenly assumes a rough resemblance to a black-and-white checker-board. Instead of the two colors changing at once into an even medium gray the process of mixture takes on a very decided black-and-white phase, suggesting that the resulting gray is due to the stimulation of two distinct retinal elements.

The tendency throughout Mr. McDougall's papers is to emphasize the part played in light- and color-vision by the cortex. Whenever possible he explains in terms of cortical attention, and he apparently feels that it is a commendable simplicity in his theory to assume as few retinal processes as possible and to refer all further variations to purely central fusions and suppressions.

Attention seems to be the refuge from a great many psychological tangles, since there is nothing which it cannot be made to explain. The fluctuation of attention is the very basis of our psychic life, it is the fundamental problem which holds the others in solution, and it is just on this account that it ought to be avoided as an explanation. No one has a right to resort to an ultimate principle until all hope of a more special explanation has failed. The tendency of scientific theory is to pass from the vague generality to the specific cause, and in dealing with sense-discrimination it has moved steadily away from the explanation in cortical terms towards that in peripheral terns. It is a more exact and intelligible mode of thought to conceive of sense differences as determined by structural differences in the sense-organs, than to suppose that they are perceived by some deft and mysterious intelligence in the cortex. Although no general considerations of this sort can prove or disprove any particular theory, yet they can lay out the direction of progress for that theory.

In comparing the retinal theories of Hering, Muller, Franklin, with the psychical of Young-McDougall, we may say that the former are forward-moving theories and the latter is a step backward. Mr. McDougall's method may be thoroughly safe, but it will never be illuminating. The Hering theory as a type is in the line of progress, and although there may be difficulties with its precise formulation it must still be the preferable hypothesis.

Mr. McDougall's criticisms have a positive value in searching so minutely as they do the frailties of the Hering theory, and in reminding psychologists of the inadequacy of any color-theory which has yet been proposed.

Kate Gordon.

UNTVERstry of Chicago. 